CONGENITAL HEART DISEASE

\title{
Health related quality of life in adults with repaired tetralogy of Fallot: psychosocial and cognitive outcomes
}

\author{
L Daliento, D Mapelli, G Russo, P Scarso, F Limongi, P lannizzi, A Melendugno, E Mazzotti, B Volpe
}

Heart 2005;91:213-218. doi: 10.1136/hrt.2003.029280

\begin{abstract}
Objective: To assess the health related quality of life of patients who were operated on during childhood for total correction of tetralogy of Fallot, focusing on the psychosocial and cognitive outcomes.

Patients: 54 patients $(24$ men and 30 women, mean (SD) age 32 (4) years), operated on for total correction of tetralogy of Fallot at mean age of 8.2 years, underwent a cardiological examination, psychological assessment (semistructured interview, Minnesota multiphasic personality inventory), evaluation of quality of life (36 item short form health survey), and neuropsychological assessment with an extensive neuropsychological battery of tests. Results: Psychological characteristics - (1) a lower than normal academic level, (2) a job inadequate for educational level, (3) a preference for an overprotective familiar setting, and (4) a difficulty communicating own corporal image. Denial of the cardiopathy was found to be a common behaviour to normalise functioning. Very few patients had a deficit in memory, learning, or attention functions; rather, patients had a deficit in the executive functions, problem solving, and planning strategies.

Conclusions: Despite a satisfactory health related quality of life, there are residual psychological and social problems in addition to impaired cognitive outcomes in the presence of a normal intelligence quotient.
\end{abstract}

See end of article for authors' affiliations

$\mathrm{T}$ he adult population with congenital heart disease has increased in the past 20 years because of advances in congenital heart surgery. ${ }^{1}$ Early surgical results are easy to quantify because of two alternative conditions, death or survival, unlike late surgical results, which are difficult to define because of the many conditions used to determine the health status, such as physical, mental, and social domains.

The prolongation of life is not always synonymous with improved quality, despite the good intentions of medical practitioners. Physical and psychological problems are present in this population. ${ }^{2}{ }^{3}$ Cognitive impairments after cardiac surgery are often found in older patients with congenital heart disease, particularly in those with cyanotic lesions. ${ }^{45} \mathrm{~A}$ complete, objective evaluation of the health related quality of life of this community is complex and it is the result of an assimilation of clinical and non-clinical data. ${ }^{6}$

The aim of this study was to assess by means of an interdisciplinary approach the health related quality of life of adult patients who were operated on (for total correction of tetralogy of Fallot) at a young age, giving particular attention to psychological and cognitive outcomes.

\section{PATIENTS AND METHODS}

Sixty eight consecutive patients, who underwent surgical correction of tetralogy of Fallot by right epicardial ventriculotomy between 1970 and 1986 at the department of cardiovascular surgery of the University of Padua at a mean age of 8.2 years (range 3 months to 40 years), were asked to participate in this study during an annual programmed cardiac clinical follow up. Fourteen of them were excluded: three for Down's syndrome, one for abnormal psychomotor development, and 10 because they did not want to be enrolled in the study. Fifty four patients gave their written consent. The research protocol was approved by the local ethics committee. There were 24 men and 30 women. The mean (SD) age was $32(4)$ years. The mean (SD) duration of post-surgical follow up was 25 (4) years. Each patient agreed

to be assessed one time in the outpatient clinic of the division of cardiology of Padua University in 2002. The programme called for a definition of cardiac morphofunctional status, stratification of arrhythmic risk, psychological assessment, quality of life assessment, and neuropsychological assessment on the same day.

Definition of morphofunctional status and arrhythmic risk stratification

All patients were chosen because they had satisfactory surgical results in terms of residual intracardiac shunt (ratio of pulmonary to systemic blood flow less than 1.5), no significant transpulmonary pressure gradient, an estimated right ventricular pressure at cross sectional and Doppler echocardiography $<45 \mathrm{~mm} \mathrm{Hg}$, and an ability index $<3$.

During the echocardiographic examination the following parameters were calculated: end diastolic volume and ejection fraction of the left ventricle by an ellipsoid biplane area-length model derived from left ventricular images in an apical four chamber view ${ }^{7}$; and end diastolic and end systolic right ventricle volumes by an area-length method derived from orthogonal planes (apical four chamber and short axis subcostal views). Levine's formula gives right ventricular volume as two thirds times the area in one view multiplied by the length in the other view and its ejection fraction. ${ }^{8}$ Valve regurgitation and stenosis were evaluated by continuous wave Doppler and pulsed wave Doppler. Images were obtained with a Hewlett Packard echocardiograph (Sonos 5500; Hewlett Packard, Andover, Massachusetts, USA). Second harmonic images were acquired with a $1.8 / 3.6 \mathrm{MHz}$ or $2.1 / 4.2 \mathrm{MHz}$ imaging frequency that was chosen to optimise image quality.

Abbreviations: $I Q$, intelligence quotient; $M M P I-2$, Minnesota multiphasic personality inventory; SF-36, 36 item short form health survey 
Arrhythmic risk (low and high risk level) was stratified by means of a basic ECG (not filtered QRS duration, QT dispersion) from 24 hour ECG Holter monitoring with a three channel tape recorder and a signal averaging ECG (filtered QRS duration, presence of late potentials) recorded with a Marquette MAC 15 system (Marquette Electronics Inc, Milwaukee, Wisconsin, USA). We considered patients to be at increased risk of life threatening arrhythmias if they had one episode of sustained ventricular tachycardia or had at least two of the following parameters: QRS duration more than $180 \mathrm{~ms}$, QT dispersion more than $80 \mathrm{~ms}$, presence of late potentials, or end diastolic right ventricular volume more than $120 \mathrm{ml} / \mathrm{m}^{2}$.

\section{Psychological and quality of life assessments}

Psychological assessment was based on a 30 minute semistructured interview and administration of two questionnaires: the Minnesota multiphasic personality inventory $(\text { MMPI- } 2)^{10}$ and the 36 item short form health survey (SF36). ${ }^{11}$ During the interview the patients were first informed about the aim of the research. Secondly, psychological, social, and economic areas were investigated through questions about actual family status, educational level, and work. After that, the two questionnaires, MMPI-2 and SF-36, were given to the patient.

The MMPI-2 is an effective and reliable test constructed to evaluate the most significant structural characteristics of personality. It comprises a self administered questionnaire of 567 statements to which the patient must respond "true" or "false". The patient must be at least 18 years of age. The administration time for the test is about one and a half hours. The test is composed of three scales of validity ( $\mathrm{L}$, lie; $\mathrm{F}$, infrequency; K, correction), 10 base clinical scales, and 15 clinical content scales. For psychodiagnostic purposes and to achieve maximum discrimination, we considered the entire profile determined by both the 13 base scales and the 15 subject scales. The scales of the test are standardised according to a normal distribution ( $\mathrm{T}$ scores). Scores above the 65th centile are considered clinically significant. The profiles of the scales hypochondriasis, psychopathic deviate, psychoasthenia, schizophrenia, and hypomania were corrected with the $\mathrm{K}$ scale.

The SF-36 was worded to evaluate some prominent conceptions about health, independently from age, health status, and treatment. The SF-36 has one multi-item scale that assesses eight health domains: physical activity, status and physical health, physical pain, general health, vitality, social activities, role and emotive status, and mental health and health condition changes. The SF-36 test has an acceptable internal consistency and retest reliability. In our study we used the well validated Italian version of SF-36. ${ }^{12}$

Table 1 Summary of the neuropsychological tests and description of the cognitive domains evaluated

\begin{tabular}{ll}
\hline Test & Cognitive domains \\
\hline Tower of London & Planning, executive functions \\
Trial making test B & $\begin{array}{l}\text { Attention shifting, psychomotor } \\
\text { speed, response inhibition }\end{array}$ \\
Raven & Problem solving ability, IQ \\
Trial making test A & Attention shifting, psychomotor \\
& speed, response inhibition \\
Calculation & Arithmetical abilities \\
Verbal fluency & Linguistic abilities, lexical access \\
Attentive matrices & Selective and sustained attention \\
Digit span (forward) & Short term memory \\
Logical story & Long term memory \\
Corsi blocks & Spatial memory, visual attention \\
Paired associate word learning & Learning and memory \\
\hline IQ, intelligence quotient. &
\end{tabular}

\section{Neuropsychological assessment}

Neuropsychological status was assessed individually by experienced neuropsychologists with a well validated battery of 11 tests to investigate all cognitive domains such as learning, memory, psychomotor speed, attention, concentration, reasoning, calculation, and executive function (table 1). The assessment test lasted one hour, with each of the 11 tests being given to the patient one after the other in the same order.

The trial making test ${ }^{13}$ is given in two parts, A and B. The patient must first draw lines to connect consecutively numbered circles on one sheet (part A) and then connect the same numbered and lettered circles on another work sheet by alternating between the two sequences (for example, 1-A, 2-B, in part B). This is a test to evaluate motor speed attention functions and switching ability.

The digit span test, a subtest of the Wechsler memory scale, ${ }^{14}$ is the format used most often for measuring span of immediate verbal recall. The test consists of seven (from two digits to eight digits) pairs of random number sequences that the examiner reads aloud at the rate of one a second. The patient's task is to repeat each sequence exactly as it is given.

The logical story test is a memory test to investigate the long term memory on immediate recall. The examiner reads a story and after reading asks the patient for immediate free recall.

The verbal paired associates test from the revised edition of the Wechsler memory scale ${ }^{15}$ consists of word pairs that are read to the patient with one or more recall trials, in which the first of the pair is presented for the patient to give the associate word. This task investigates verbal memory and learning.

The Corsi block tapping test ${ }^{16}$ for measuring orientation and spatial attention consists of black cubes fastened in a random order to a black board. Each time the examiner taps the blocks in a prearranged sequence, the patient must attempt to copy this tapping pattern.

The attentive matrices test $t^{17}$ is a valid instrument to measure selective and the sustained attention. It consists of a series of patterns of numbers; the patient is required to check the numbers to find a target number (from one to four digits).

In the phonemic verbal fluency test ${ }^{18}$ patients are required to say words beginning with a particular letter of the alphabet (for example, C, P, S) for a specific time (one minute for each letter). Although it is a test to measure lexical access, phonemic fluency places higher demands on frontally mediated strategic search processes.

The calculation test ${ }^{19}$ consists of four blocks of arithmetical operations: addition, subtraction, multiplication, and division.

The Tower of London test ${ }^{20}$ is a specific task to investigate executive functions and planning ability. The test is a problem solving task that requires patients to rearrange three coloured rings (in accordance with some very simple rules) from their initial position on three upright sticks to a new set of predetermined positions. Patients are instructed to try to achieve the goal arrangement in as few moves as possible.

Raven's progressive matrices ${ }^{21}$ is a multiple choice test. It consists of a series of visual pattern matching and analogy problems pictured in no representational designs. It requires the patient to conceptualise spatial, design, and numerical relations ranging from the obvious and concrete to very complex and abstract. Patient is presented with a set of 12 incomplete figures and their task is to complete the set by choosing one of the six response alternatives given below the figure. The Raven test also gives an intelligence quotient (IQ). 


\begin{tabular}{|ll|}
\hline Table 2 Clinical characteristics of the study group & \\
\hline Men/women & $24(44 \%) / 30(56 \%)$ \\
Age (years) & $32(4)$ \\
Duration of post-surgical follow up (years) & $25(4)$ \\
Preoperative data & $15(27 \%)$ \\
Blue spells & $34(63 \%)$ \\
Aortic saturation at rest $80-90 \%$ & $20(37 \%)$ \\
Palliative intervention & \\
Perioperative data & $0.86(0.4)$ \\
Body surface area $\left(\mathrm{m}^{2}\right)$ & $104(26) \mathrm{n}$ \\
Duration of total circulatory arrest (min) & $59(21)$ \\
Duration of cardiac arrest (min) & 2 \\
Late post-surgical follow up & $64(16)$ \\
Mean ability index & $59(6)$ \\
LVEDV (ml/ $\mathrm{m}^{2}$ ) & $111(37)$ \\
LV ejection fraction (\%) & $53(7)$ \\
RVEDV (ml/ $\mathrm{m}^{2}$ ) & $13(24 \%)$ \\
RV ejection fraction (\%) & 0 \\
High risk patients & $2(3 \%)$ \\
Sustained ventricular tachycardia & $3(5 \%)$ \\
QRS duration $>180 \mathrm{~ms}, \mathrm{QT}$ dispersion $>80 \mathrm{~ms}, \mathrm{RVEDV}>120 \mathrm{ml} / \mathrm{m}^{2}$ & $6(11 \%)$ \\
QRS duration $>180 \mathrm{~ms}, \mathrm{QT}$ dispersion $>80 \mathrm{~ms}$ & \\
QRS duration $>180 \mathrm{~ms}, \mathrm{RVEDV}>120 \mathrm{ml} / \mathrm{m}^{2}$ & \\
QT dispersion $>80 \mathrm{~ms}$, RVEDV $>120 \mathrm{ml} / \mathrm{m}^{2}$ & \\
\hline LV, left ventricular; LVEDV, left ventricular end diastolic volume; RV, right ventricular; RVEDV, right ventricular end \\
diastolic volume.
\end{tabular}

\section{Statistical methods}

Clinical data were expressed as mean (SD). Neuropsychological performance was assessed by calculating the Z score, comparing each row score with the mean (SD) of the reference control population normalised for sex, age, and education. Computerised statistical analysis was undertaken with the use of StatView 5.0.1 for Window (SAS Institute Inc, Cary, North Carolina, USA). Groups were compared with a univariate analysis, the Mann-Whitney test for unpaired data. Correlation between two variables was evaluated by means of linear regression analysis and expressed as the correlation coefficient $(r)$.

\section{RESULTS}

\section{Clinical findings}

All patients underwent cardiopulmonary bypass and deep hypothermia $\left(22^{\circ} \mathrm{C}\right.$ rectal temperature). The mean (SD) body surface area was $0.86(0.4) \mathrm{m}^{2}$. The mean (SD) total circulatory arrest and cardiac arrest times were 104 (26) minutes and 59 (21) minutes, respectively. Twenty patients $(37 \%)$ had a palliative operation during the first two years of life and 15 of them (75\%) had blue spells. In the other 34 patients aortic oxygen saturation before surgery varied between $85 \%$ and $90 \%$ at rest.

No patients had major complications after surgery and the mean (SD) period in the intensive care unit was 6 (3) days. No patients had any clinically detectable cerebral complications such as ictus or seizure during hospitalisation.

Table 3 Results of SF-36 compared with a normative group of controls

\begin{tabular}{llll}
\hline Health domain & Patients & Controls & p Value \\
\hline Physical activity & $84.29(17.19)$ & $94.75(13.18)$ & 0.003 \\
Status and physical health & $84.05(25.04)$ & $90.22(25.19)$ & NS \\
Physical pain & $82.43(20.39)$ & $81.39(24.62)$ & NS \\
General health & $67.27(20.27)$ & $75.78(16.14)$ & NS \\
Vitality & $68.43(14.98)$ & $67.75(16.8)$ & NS \\
Social activities & $78.07(22.15)$ & $81.58(19.34)$ & NS \\
Role and emotive status & $78.21(26.74)$ & $85.39(29.49)$ & NS \\
Mental health & $73.74(16.45)$ & $72.72(16.97)$ & NS \\
\hline \multirow{2}{*}{ NS, not significant. } & & & \\
\hline
\end{tabular}

Standard ECG showed all patients in sinus rhythm and with complete right bundle branch block. Twenty four patients were considered at high risk of life threatening arrhythmias (table 2). Four of 13 patients who had at least one episode of ventricular tachycardia, documented by means of 24 hour ECG Holter monitoring or in emergency room, had a successful radiofrequency ventricular ablation and three had an implantable cardioverter-defibrillator. During a mean follow up of 36 months (range 24-48 months) no discharge of the device was recorded.

\section{Psychological and quality of life assessments Psychological interview}

All patients agreed to have the interview. The mean (SD) duration of education was 11 (3) years: 18 (34\%) patients satisfied compulsory schooling; $33(61 \%)$ had a General Certificate of Education, and $3(5 \%)$ took a degree (in mathematics, literature, and computer science); 42 (78\%) patients had a job: 27 (49\%) were office workers and 16 $(29 \%)$ were unskilled workers; $4(8 \%)$ were unemployed and $8(14 \%)$ were students; $47(87 \%)$ declared they had a satisfactory social position.

Measurement of the quality and stability of psychoaffective relationships found that $35(65 \%)$ were married and described their partner as a very important supportive figure; 19 (35\%) were single, without a stable affective relationship.

Findings of specific psychological events related to cardiac condition were that $37(68 \%)$ patients did not remember the operation because of the very young age; $43(80 \%)$ reported frequent absences from primary school because of the various hospitalisations secondary to the cardiopathy; 49 (90\%) stressed physical restrictions during infancy and childhood; $43(80 \%)$ remembered adolescence as a difficult time from an emotional point of view because of (particularly for the girls) the presence of scarring in the thorax, which was a problem for socialising; $38(70 \%)$ patients reported a positive and very active self image.

\section{SF-36}

In the quality of life questionnaire no significant differences were found from the normal population, excluding physical activity, because for these patients mild right ventricular dysfunction and reduced physical capability were documented. Table 3 summarises the results. 


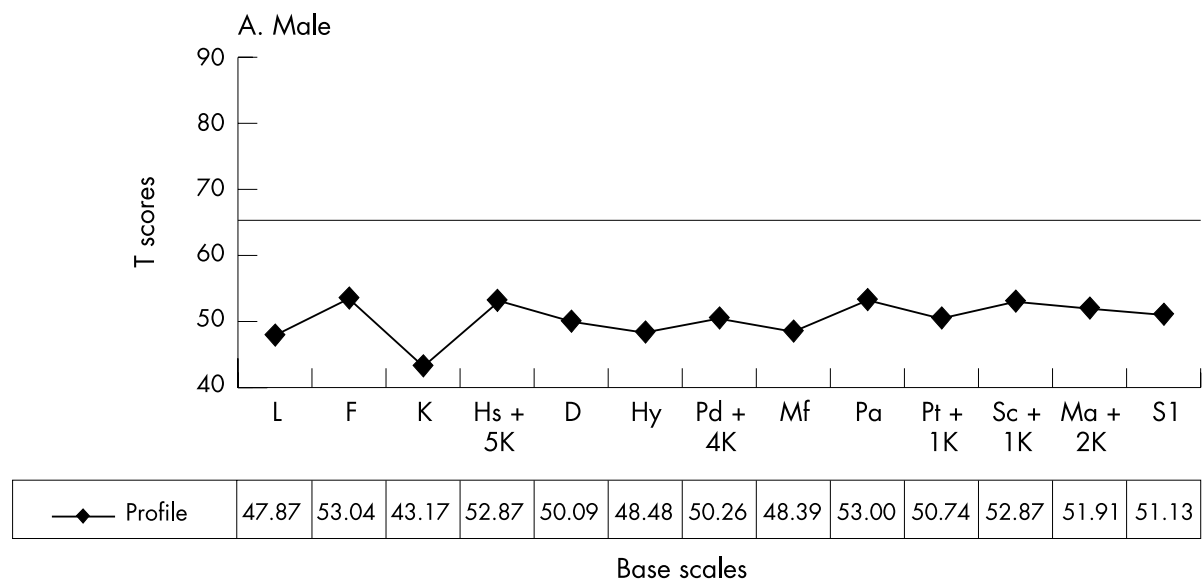

Figure 1 Results of the Minnesota multiphasic personality inventory (MMPI-2), base scales, in (A) men and (B) women. Scores $>65$ were considered pathological. D, depression; $\mathrm{F}$, infrequency; $\mathrm{Hs}$, hypochondriasis; $\mathrm{Hy}$, conversion hysteria; $\mathrm{K}$, defensiveness; L, lie; Ma, hypomania; Mf, masculinity-femininity; $\mathrm{Pa}$ paranoia; Pd, psychopathic deviate; $\mathrm{Pt}$, psychoasthenia; Sc, schizophrenia; SI, social introversion.

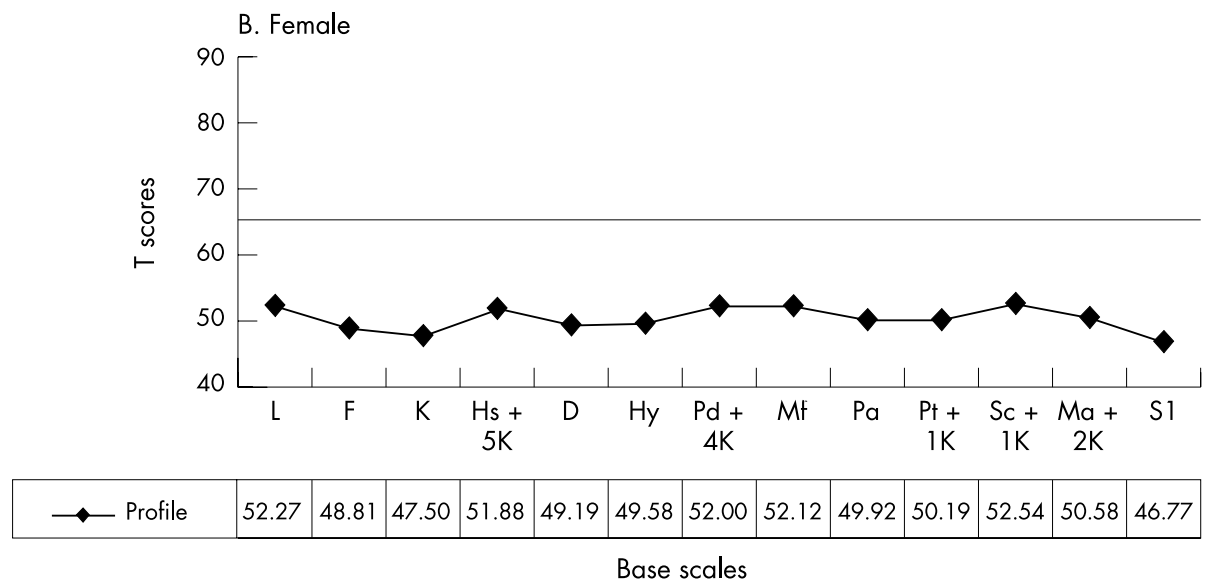

MMPI

No pathological traits of personality were found. Figures 1 and 2 summarise the results.

\section{Neuropsychological assessment}

Fifty four patients completed the cognitive assessment. A very low percentage of patients had a deficit in memory learning and attention function (paired associate word learning test, Corsi blocks test, logical story test, digit span test, and attentive matrices test). On the other hand, patients had a deficit in tasks that involved executive function, problem solving, and planning strategies (verbal fluency test, calculation test, Raven test, trial making test $\mathrm{A} / \mathrm{B}$, and Tower of London test). In particular 29 (53\%) patients altered in the Tower of London test: to solve this test, planning ability is required (fig 3 ).

\section{Correlations between cardiologic clinical data, psychosocial findings, and cognitive outcome}

No correlations were found between psychosocial and postsurgical cardiac morphofunctional findings and arrhythmic risk stratification.

Preoperative clinical data and cognitive outcomes were significantly correlated. In particular, patients with a clinical history of blue spells in infancy performed poorly in the trial making test and the Tower of London test $(\mathrm{U}=104.00$, $p<0.005$, and $U=184.00, p<0.05$, respectively). A correlation was found between the scale of low self esteem and low level of education with the trail making test
( $\mathrm{p}<0.05, r=0.71)$. Lastly, low self esteem correlated with hypoxic blue spells in infancy ( $\mathrm{p}<0.05, r=0.63$ ).

\section{DISCUSSION}

Surgical outcome of total correction of tetralogy of Fallot has dramatically improved over the past 20 years, and this has resulted in a longer life span, with most children surviving to adulthood. Actuarial 10, 20, 30, and 36 years survival rates of a large series of patient survivors one year after surgical repair are $97 \%, 94 \%, 89 \%$, and $85 \%$, respectively. ${ }^{22}$ But if the long term results of the surgical repair were judged on the presence of a normal cardiac anatomy or electrophysiological findings the score would not be particularly satisfactory: $60 \%$ of patients had substantial right ventricular dilatation five years after surgery, which becomes $90 \%$ after 15 years, as a consequence of pulmonary and tricuspid valve incompetence; $75 \%$ of patients had ventricular or supraventricular arrhythmias on 24 hour ECG Holter monitoring with an incidence of sudden death of $0.3-0.4 / 1000 /$ year. ${ }^{23}$

The probability that in the future, for many of these patients, further investigations and surgical interventions will be necessary is very high. Nevertheless, the majority of long term survivors described their general health perception as excellent or good, independent of post-surgical sequelae.

According to the World Health Organization, ${ }^{24}$ the health related quality of life $^{4}$ is a multidimensional concept that encompasses various domains such as physical health, psychological and social functioning, and occupational performance. Each of these domains embraces different aspects, which can be quantitatively studied. In patients who 


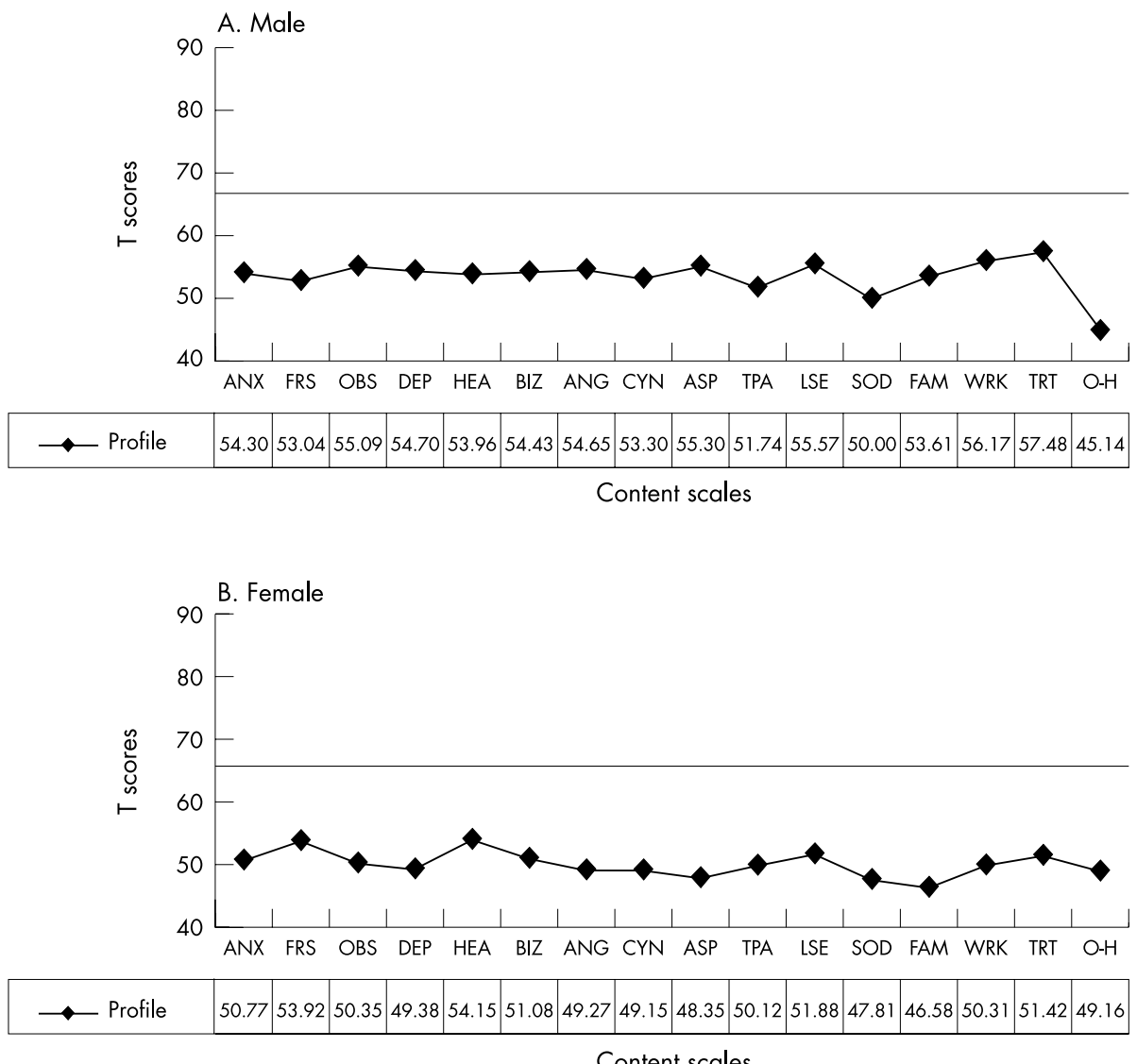

Figure 2 Results of MMPI-2, content scales, in (A) men and (B) women. Scores $>65$ were considered pathological. ASP, antisocial practices; ANG, anger; ANX, anxiety; CYN, cynicism; BIZ, bizarre mentation; DEP, depression; FAM, family problems; HEA, health concerns; FRS, fears; LSE, low self esteem; OBS, obsession; O-H, overcontrolled hostility; SOD, social discomfort; TPA, type A; TRT, negative treatment indicators; WRK, work interference.

Content scales

underwent surgery for total correction of tetralogy of Fallot, the domain of physical health has been profoundly investigated. Right ventricular dysfunction and electrical ventricular instability were identified as the most important clinical prognostic factors. Up until now, few systematic quantitative

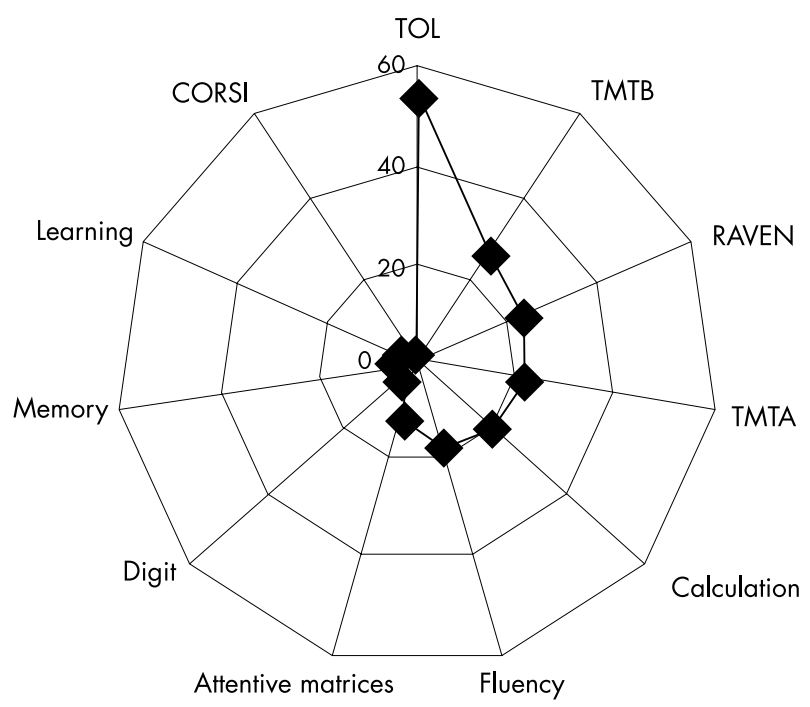

\section{Cognitive alteration}

Figure 3 Scheme of neuropsychological impairment. CORSI, Corsi blocks test; RAVEN, Raven test; TMB, trial making test $B$; TMTA, trial making test $A$; TOL, Tower of London. data about the other main domains were available .Various authors $^{25-28}$ reported data regarding health and quality of life of adult patients operated on for total correction of tetralogy of Fallot in infancy and childhood, based on a structured interview regarding external life conditions, interpersonal relationships, and internal psychological states. No significant differences were found from the normal population, apart from some of them requiring additional educational help at school. These studies indicate that, over time, patients may adapt to their physical status and denial is a common behaviour to normalise functioning.

Nevertheless, the absence of personality trait profiles or examination of cognitive function in these studies limits the psychological and intellectual assessment of these patients and the reconstruction of the dynamics of their development. Our study group spent more time at school, even though the academic level was lower than that of the normal population (66\% of patients stopped at the General Certificate of Education versus $37 \%$ of the mean value of the National Statistics Institute), and very few people graduated from a university (3\% versus $11 \%$ of the national population). All patients were employed, but the majority did not have a job adequate to their level of education. Some patients continued to live with their family, preferring the familiar setting which is protective from an economical and social point of view. These patients had difficulty talking about their operation: they could not remember it because they were so young at the time, but all could remember that they lived somewhat isolated because of the various admissions to the hospital and of being physically limited. Adolescence was another difficult period because the scar was a handicap to embark on friendship and close relationships. During the interview the patients had difficulty in speaking about the body overall 
because they put the attention exclusively on the heart and its sudden rhythm modification.

Previous studies reported normal values of intellective parameters, measured by the IQ, for patients with congenital heart diseases, ${ }^{29}$ with mildly reduced scores only in the cyanotic population. ${ }^{40-32}$ Also in our series the IQ given by Raven's progressive matrices was in the normal range in more than two thirds of patients, but a more complete investigation showed impaired cognitive abilities such as executive functions, problem solving, and planning strategies. In particular, planning is defined as the ability to organise cognitive behaviour in time and space: it is necessary in situations in which a goal must be achieved through a series of intermediate steps, each of which individually does not lead directly towards the goal. Neuropsychological studies ${ }^{33}$ have shown that lesions in the frontal lobe, mainly the prefrontal cortex, which is located anterior to the motor map, may cause problems with planning. Recently, positron emission tomography, single photon emission computed tomography, and functional magnetic resonance imaging studies confirmed that brain activity during the Tower of London planning task is located mainly in the prefrontal area, particularly in the dorsolateral prefrontal cortex. ${ }^{34}$ The educational level has no influence on the results; in fact patients with a degree have cognitive impairment as well.

On the other hand, the correlation between low self estimation, deficit in execution of functions, and hypoxic blue spells supports the presence of an organic pathological substrate and not a consequence of psychosocial themes only. The difficulty in understanding or considering at the same time more aspects to solve a problem may worsen the inadequacy of the self image. Moreover, they were able to obtain a satisfactory educational level and social functioning as a result of strong personal engagement, their family investment had to be "normal", and they had "to be able to live like the others". Patients operated on for congenital heart disease are spoken of as "high achievers". During the interview our patients' diffuse hyperactivity suggested that depression was not a possibility because they found mourning difficult due to a prenatal lack, which could be associated with a transgenerational fault (presence of cardiopathy in the family). The inability to mourn is one of the main aims of psychotherapeutic intervention.

Many factors affect how children with congenital heart disease grow up, such as native cardiac defects, age at operation, type and technique of operation, family setting, and socioeconomic conditions. Knowledge and awareness of these factors is key in attaining adequate prevention.

\section{Limitations}

The study may be limited somewhat by our inability to compare the psychological and neurocognitive assessments before the surgical correction as recent studies have, because we analysed an adult population that underwent surgical repair from the early 1970s to the late 1980s.

We were obliged to compare all the patients with preestablished social classes (according to the national referees), but we must not forget that the patient may act differently from the group. For this reason, the semistructured psychological interview is important because it helps to define each person with his or her own personal history that depends not only on the disease but also on surrounding factors.

We thank Mrs Barbara Hildebrand for revision of the manuscript.

\footnotetext{
Authors' affiliations

L Daliento, G Russo, P Scarso, A Melendugno, E Mazzotti, B Volpe, Department of Cardiology, University of Padua, Italy
}

D Mapelli, F Limongi, P lannizzi, Department of General Psychology, University of Padua

\section{REFERENCES}

1 Daliento L, Mazzotti E, Mongillo E, et al. Life expectancy and quality of life in adult patients with congenital heart disease. Ital Heart J 2002;3:339-47.

2 Brandhagen DJ, Feldt RH, Williams DE. Long term psychologic implication of congenital heart disease: a 25 years of follow-up. Mayo Clin Proc $1991 ; 66: 474-9$.

3 Cox D, Lewis G, Stuard G, et al. A cross-sectional study of the prevalence of psychopathology in adults with congenital heart disease. J Psychosom Res 2002:52:65-8.

4 Wray J, Sensky T. Congenital heart disease and cardiac surgery in childhood: effect on cognitive function and academic ability. Heart 2001;85:687-91.

5 Oates RK, Simpson JM, Cartmill TB, et al. Intellectual function and age of repair in cyanotic congenital heart disease. Arch Dis Child 1995:72:298-301.

6 Fallowfield L. The quality of life: the missing measurement in health care. London: Souvenir Press, 1990.

7 Schiller NB. Two dimensional echocardiographic determination of left ventricular volume, systolic function and mass: summary and discussion of the 1989 recommendations of the American Society of Echocardiography. Circulation 1991;84:280-7.

8 Levine RA, Gibson TC, Aretz T, et al. Echocardiographic measurement of right ventricle. Circulation 1984;69:497-505.

9 Daliento L, Rizzoli G, Menti L, et al. Accuracy of electrocardiographic and echocardiographic indices in predicting life-threatening ventricular arrhythmias in patients operated on for tetralogy of Fallot. Heart 1999;81:650-5.

10 Hathaway SR, McKinley JC. Minnesota multiphasic personality inventory 2 manual. Florence: Organizzazioni Speciali, 1995.

11 Ware JE, Sherbourne CD. The MOS 36-item short-form health survey (SF-36). Conceptual framework and item selection. Med Care 1992;30:473-83.

12 Apolone G, Cifani S, Liberati MC, et al. Questionario sullo stato di salute SF 36. Traduzione e validazione in italiano (Progetto IQOLA). Metodologia e didattica Clinica 1997;5:86-94.

13 Reiatn RM. Validity of trail making test as an indication of organic brain damage. Percept Mot Skills 1958;8:271-6.

14 Wechsler D, Stone CP. Wechsler memory scale II manual. New York: The Psychological Corporation, 1974.

15 Wechsler D. Wechsler memory scale: revised manual. San Antonio: The Psychological Corporation, 1987.

16 Milner B. Interhemispheric differences in the localization of psychological processes in man. Br Med Bull 1971;27:272-7.

17 Spinnler H, Tognoni G. Standardizzazione e taratura italiana di test neuropsicologici. Ital J Neurol Sci 1987; (suppl 8):1-20.

18 Mondini S, Mapelli D, Vestri A, et al. Esame neuropsicologico breve. Milan: Raffaello Cortina Editore (In press).

19 Basso A, Capitani E. Un test standardizzato per la diagnosi di acalculia: descrizione e valori normative. Riv Appl psicol 1979;1:551-68.

20 Shallice T. Specific impairments of planning. Philos Trans R Soc Lond B Biol Sci 1982;298:199-209.

21 Raven JC. Standard progressive matrices: sets A, B, C, D and E. London: HK Lewis, 1978

22 Nollert G, Fischlein T, Bouterwek S, et al. Long-term survival in patients with repair of tetralogy of Fallot: 36 -year follow-up of 490 survivors of the first year after surgical repair. J Am Coll Cardiol 1997;30:1374-8.

23 Garson A Jr, Randall DC, Gilette PC, et al. Prevention of sudden death after repair of tetralogy of Fallot: treatment of ventricular arrhythmias. J Am Coll Cardiol 1985:6:221-7.

24 Anon. The constitution of the World Health Organization. WHO Chron 1947;1:29.

25 Meijboom F, Sraturati A, Deckers JW, et al. Cardiac status and health-related quality of life in the long-term after surgical repair of tetralogy of Fallot in infancy and childhood. J Cardiovasc Surg 1994;1 10:883-91.

26 Ternestedt BM, Wale K, Oddsson H, et al. Quality of life 20 and 30 years after surgery in patients operated on for tetralogy of Fallot and ASD. Pediatr Cardiol 2001;22:128-32.

27 Aigueparse J, Marechal MC. Evaluation of the quality of life in adulthood of 158 patients surgically treated for tetralogy of Fallot. Arch Med Coeur Vaiss 1991;84:685-90.

28 Shampaine EL, Nadelman L, Rosenthal A, et al. Longitudinal psychological assessment in tetralogy of Fallot. Pediatr Cardiol 1990;10:135-40.

29 Eiser C. Effects of chronic illness on intellectual development. Arch Dis Child 1980;55:766-70.

30 Kallfelz HC, Kaemmerer H, Luhmer I, et al. Psychointellectual performance after correction of complex congenital heart defects. In: Walter PJ, ed. Quality of life after open heart surgery. Dordrecht: Kluwer Academic Publishers, 1992:315-21.

31 Wray J, Sensky T. Controlled study of pre-school development after surgery for congenital heart disease. Arch Dis Child 1999;80:511-6.

32 Wright M, Nolan T. Impact of cyanotic heart disease on school performance. Arch Dis Child 1994;71:64-70.

33 Shallice T, Burgess PW. Deficits in strategy application following frontal lobe damage in man. Brain 1991;114:727-41.

34 Lazeron RH, Rombouts SA, Machielsen WC, et al. Visualizing brain activation during palnning: the Tower of London test adapted for functional MR imaging. Am J Neuroradiol 2000;21:1407-14. 